www.nature.com/ja

\title{
JBIR-58, a new salicylamide derivative, isolated from a marine sponge-derived Streptomyces sp. SpD081030ME-02
}

\author{
Jun-ya Ueda ${ }^{1}$, Shams Tabrez Khan ${ }^{1}$, Motoki Takagi ${ }^{1}$ and Kazuo Shin-ya ${ }^{2}$
}

The Journal of Antibiotics (2010) 63, 267-269; doi:10.1038/ja.2010.26; published online 26 March 2010

Keywords: cytotoxicity; marine sponge; salicylamide; Streptomyces

\begin{abstract}
Marine microorganisms, particularly marine actinomycetes, have attracted considerable attention as one of the most important resources for new biologically active metabolites. ${ }^{1}$ For example, new compounds have been isolated from actinomycetes of sponge origin..$^{2-4}$ Our group was engaged in the isolation of actinobacteria from marine sponges. We have recently discovered novel compounds, namely the anthracyclines tetracenoquinocin and 5-imino aranciamycin, ${ }^{5}$ a teleocidin JBIR- $31,{ }^{6}$ the tetrapeptides JBIR-34 and $-35,{ }^{7}$ and the isoprenoids JBIR-46-48. ${ }^{8,9}$ Our intention was to support the idea that new species are capable of producing unique metabolites. For this purpose, we isolated new species of Streptomyces from marine sponges and then searched for secondary metabolites in the cultures of isolated strains. In this study, we isolated a new species (SpD081030ME-02) of Streptomyces from a Demospongiae class of marine sponge, and purified a new compound termed JBIR-58 (1, Figure 1a) from the fermentation broth of Streptomyces sp. SpD081030ME-02. We report herein the fermentation, isolation, structure elucidation and, in brief, the biological activity of $\mathbf{1}$.
\end{abstract}

Streptomyces sp. SpD081030ME-02 was isolated from a Demospongiae class of marine sponge, collected offshore of Ishigaki City, Okinawa Prefecture, Japan. To identify the species of the strain SpD081030ME02, we compared the 16S rRNA gene sequences (accession no. AB539864) with those available in the DNA Data Bank of Japan using the basic local alignment search tool. ${ }^{10}$ The strain was identified as a new species of the genus Streptomyces, as the 16S rRNA gene sequence comparison exhibited a low sequence similarity of $98 \%$ with Streptomyces chromofuscus. SpD081030ME-02 was cultured at $27^{\circ} \mathrm{C}$ for 5 days in 500-ml Erlenmeyer flasks containing $100 \mathrm{ml}$ of a medium consisting 2.5\% starch (Kosokagaku, Tokyo, Japan), 1.5\% soybean meal (Nisshin Oillio, Tokyo, Japan), $0.2 \%$ dry yeast (Mitsubishi Tanabe Pharma, Osaka, Japan), $0.4 \% \mathrm{CaCO}_{3}$ (Kozaki Pharmaceutical, Tokyo, Japan), and Diaion HP-20 (Mitsubishi Chemical, Tokyo, Japan), with $\mathrm{pH}$ adjusted to 6.2 before sterilization. The supernatant of whole broth (2l) collected by centrifugation was acidified to $\mathrm{pH} 2-3$ and extracted with EtOAc. The EtOAc layer was dried over anhydrous $\mathrm{Na}_{2} \mathrm{SO}_{4}$ and evaporated to dryness in vacuo. The residue $(2.03 \mathrm{~g})$ was dissolved with $n$-hexane- $\mathrm{CHCl}_{3}$ (6:1), $\mathrm{CHCl}_{3}, \mathrm{CHCl}_{3}-\mathrm{MeOH}$ (1:1) and $\mathrm{MeOH}$, successively. The $\mathrm{CHCl}_{3}$-soluble fraction $(487 \mathrm{mg}$ ) was purified using normal-phase medium-pressure liquid chromatography (Purif-Pack SI $30 \mu \mathrm{m}$, Moritex, Tokyo, Japan; $\mathrm{CHCl}_{3}-\mathrm{MeOH}, 99: 1$ ) and preparative TLC $\left(\mathrm{SiO}_{2} ; \mathrm{CHCl}_{3}-\mathrm{MeOH}, 19: 1\right)$ to yield $1(9.8 \mathrm{mg}$, $\mathrm{Rf}=0.43$ )

Compound 1 was obtained as a yellow powder $\left([\alpha]^{24} \mathrm{D}+72.3\right.$, c. 0.1 $\left(\mathrm{CHCl}_{3}\right), \mathrm{UV}(\mathrm{MeOH}) \lambda_{\max }(\log \varepsilon) 226$ (4.23), 286 (4.18), 297 $(4.10, \mathrm{sh})$ and $412(3.57) \mathrm{nm})$. The IR spectrum $\left(\mathrm{CHCl}_{3}\right)$ of 1 revealed the characteristic absorptions of a ketone $\left(v_{\max } 1662 \mathrm{~cm}^{-1}\right)$ and an amide $\left(1662,1624\right.$ and $\left.1431 \mathrm{~cm}^{-1}\right)$ groups. The HR-ESI-MS data of 1 gave the sodium-adduct ion at $\mathrm{m} / z 332.0746$ (calcd. for $\mathrm{C}_{14} \mathrm{H}_{15} \mathrm{NO}_{7} \mathrm{Na}$, 332.0753). The direct connectivity between protons and carbons was established by the heteronuclear single-quantum coherence spectrum, and the ${ }^{13} \mathrm{C}$ and ${ }^{1} \mathrm{H}$ NMR spectral data for $\mathbf{1}$ are shown in Table 1 . The analyses of double-quantum filtered-COSY and constant time-HMBC ${ }^{11}$ spectra revealed the structure of $\mathbf{1}$ as follows.

The proton spin coupling between an oxymethine proton $5-\mathrm{H}\left(\delta_{\mathrm{H}}\right.$ 4.57) and a methyl proton $11-\mathrm{H}\left(\delta_{\mathrm{H}} 1.57\right)$, and the sequence from an oxymethine proton $6 \mathrm{a}-\mathrm{H}\left(\delta_{\mathrm{H}} 5.09\right)$ through methylene proton $7-\mathrm{H}$ $\left(\delta_{\mathrm{H}} 2.41,2.03\right)$ to an acetal proton $8-\mathrm{H}\left(\delta_{\mathrm{H}} 5.42\right)$ were observed in the double-quantum filtered-COSY spectrum (Figure 1b). A methoxyl

${ }^{1}$ Biomedicinal Information Research Center (BIRC), Japan Biological Informatics Consortium (JBIC), Koto-ku, Tokyo, Japan and ${ }^{2}$ Biomedicinal Information Research Center (BIRC), National Institute of Advanced Industrial Science and Technology (AIST), Koto-ku, Tokyo, Japan

Correspondence: Dr K Shin-ya, Biomedicinal Information Research Center (BIRC), National Institute of Advanced Industrial Science and Technology (AIST), 2-4-7 Aomi, Koto-ku, Tokyo 135-0064, Japan.

E-mail: k-shinya@aist.go.jp or Dr M Takagi, Biomedicinal Information Research Center (BIRC), Japan Biological Informatics Consortium (JBIC), 2-4-7 Aomi, Koto-ku, Tokyo 1350064, Japan.

E-mail: motoki-takagi@aist.go.jp

Received 31 January 2010; revised 3 March 2010; accepted 5 March 2010; published online 26 March 2010 
a<smiles>CO[C@H]1C[C@H]2O[C@@H](C)C(=O)c3c(O)c(O)c(C(N)=O)c(c32)O1</smiles>

b
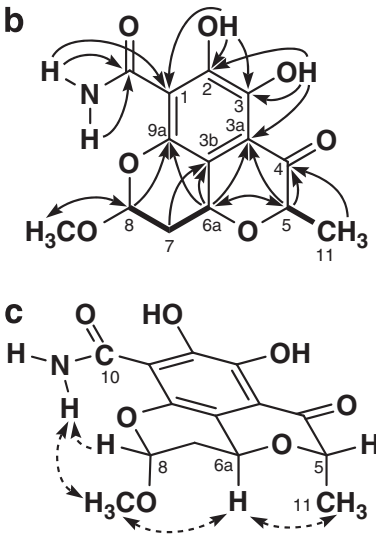

Figure 1 (a) Structure of JBIR-58 (1) and (b) key correlations in doublequantum filtered-COSY (bold lines) and constant time-HMBC (arrows) spectra of $\mathbf{1}$. (c) NOE observation for 1 (dashed arrows).

Table $1{ }^{13} \mathrm{C}$ and ${ }^{1} \mathrm{H}$ NMR data for 1

\begin{tabular}{|c|c|c|}
\hline & $\delta_{C}$ & $\delta_{H}$ \\
\hline 1 & 108.0 & \\
\hline 2 & 153.7 & \\
\hline 3 & 146.8 & \\
\hline $3 a$ & 112.6 & \\
\hline $3 b$ & 112.0 & \\
\hline 4 & 202.9 & \\
\hline 5 & 76.0 & $4.57(q, 7.5)$ \\
\hline $6 a$ & 57.6 & $5.09(\mathrm{dd}, 12.5,6.0)$ \\
\hline 7 & 31.6 & $2.41(\mathrm{ddd}, 12.5,6.0,2.5) ; 2.03(\mathrm{td}, 12.5,2.5)$ \\
\hline 8 & 100.2 & $5.42(t, 2.5)$ \\
\hline $9 a$ & 139.0 & \\
\hline 10 & 171.6 & \\
\hline 11 & 14.6 & $1.57(\mathrm{~d}, 7.5)$ \\
\hline $8-O-\mathrm{CH}_{3}$ & 56.5 & $3.52(\mathrm{~s})$ \\
\hline $2-\mathrm{OH}$ & & 13.80 (br s) \\
\hline $3-\mathrm{OH}$ & & $11.20(\mathrm{br} \mathrm{s})$ \\
\hline $10-\mathrm{NH}_{2}$ & & 8.21 (br s); 6.48 (br s) \\
\hline
\end{tabular}

${ }^{13} \mathrm{C}(150 \mathrm{MHz})$ and ${ }^{1} \mathrm{H}(600 \mathrm{MHz}) \mathrm{NMR}$ spectra were measured using a NMR System $600 \mathrm{NB}$ $\mathrm{CL}$ (Varian, Palo Alto, $\mathrm{CA}, \mathrm{USA}$ ) in $\mathrm{CDCl}_{3}$, and the solvent peak was used as an internal standard $\left(\delta_{\mathrm{C}} 77.0, \delta_{\mathrm{H}} 7.26\right.$ p.p.m.).

proton $\left(\delta_{\mathrm{H}} 3.52\right)$ and 5-H were long-range coupled to C-8 $\left(\delta_{\mathrm{C}} 100.2\right)$ and $\mathrm{C}-6 \mathrm{a}\left(\delta_{\mathrm{C}} 57.6\right)$, respectively, indicating the 3,7-dioxaoctane structure. The HMBCs from $5-\mathrm{H}$ to a carbonyl carbon $\mathrm{C}-4\left(\delta_{\mathrm{C}}\right.$ 202.9) and an aromatic carbon $\mathrm{C}-3 \mathrm{a}\left(\delta_{\mathrm{C}} 112.6\right)$, from $6 \mathrm{a}-\mathrm{H}$ to three aromatic carbons $\mathrm{C}-3 \mathrm{a}, \mathrm{C}-3 \mathrm{~b}\left(\delta_{\mathrm{C}} 112.0\right)$ and $\mathrm{C}-9 \mathrm{a}\left(\delta_{\mathrm{C}} 139.0\right)$, and from $8-\mathrm{H}$ to $\mathrm{C}-9 \mathrm{a}$ established a pyranopyran structure.

The long-range coupling from an amide proton $1-\mathrm{NH}\left(\delta_{\mathrm{H}} 6.48\right)$ to a carbonyl carbon $\mathrm{C}-10\left(\delta_{\mathrm{C}} 171.6\right)$ and an aromatic proton C-1 $\left(\delta_{\mathrm{C}}\right.$
108.0), from a hydroxyl proton $2-\mathrm{OH}\left(\delta_{\mathrm{H}} 13.80\right)$ to three aromatic carbons $\mathrm{C}-1, \mathrm{C}-2\left(\delta_{\mathrm{C}} 153.7\right)$ and $\mathrm{C}-3\left(\delta_{\mathrm{C}} 146.8\right)$, and from a hydroxyl proton $3-\mathrm{OH}\left(\delta_{\mathrm{H}} 11.20\right)$ to three aromatic carbons $\mathrm{C}-2, \mathrm{C}-3$ and $\mathrm{C}-3 \mathrm{a}$ indicated that a hydroxysalicylamide unit conjugated to the pyranopyran unit (Figure 1b). Although direct connectivity between $\mathrm{C}-1$ and $\mathrm{C}-9 \mathrm{a}$ was not observed in COSY and HMBC, the NOEs among $8-\mathrm{H}, 8-\mathrm{O}-\mathrm{CH}_{3}$ and an amide proton $1-\mathrm{NH}\left(\delta_{\mathrm{H}} 8.21\right)$ suggested the conjugation between $\mathrm{C}-1$ and $\mathrm{C}-9 \mathrm{a}$ (Figure 1c). Thus, the planar structure of 1 was determined as shown in Figure la.

The relative configurations were assigned on the basis of coupling constants and the analysis of NOE experiments. The large coupling constant $(J=12.5 \mathrm{~Hz})$ between $6 \mathrm{a}-\mathrm{H}$ and $7-\mathrm{H}$ (axial, $\delta_{\mathrm{H}} 2.03$ ) indicated that $6 \mathrm{a}-\mathrm{H}$ is in axial location. The NOEs between $6 \mathrm{a}-\mathrm{H}$ and $11-\mathrm{H}$, and between $6 \mathrm{a}-\mathrm{H}$ and $8-\mathrm{O}-\mathrm{CH}_{3}$, also revealed that both the methyl group on $\mathrm{C}-5$ and the methoxyl group on $\mathrm{C}-8$ are in the same location as $6 \mathrm{a}-\mathrm{H}$ (Figure 1c).

To evaluate the cytotoxic activity of $\mathbf{1}$ against human cervical carcinoma HeLa cells, the activity was tested by WST-8 [2-(2-methoxy-4-nitrophenyl)-3-(4-nitrophenyl)-5-(2,4-disulfophenyl)-2H-tetrazolium, monosodium salt] colorimetric assay (Cell Counting Kit, Dojindo, Kumamoto, Japan). As a result, 1 showed cytotoxic effect against HeLa cells with an $\mathrm{IC}_{50}$ value of $28 \mu \mathrm{m}$ for $48 \mathrm{~h}$.

We have isolated a new salicylamide derivative having pyranoisochromone structure from the culture of a new species of Streptomyces. The pyranoisochromone derivatives have been reported to have been isolated as berkelic acid ${ }^{12}$ from extremophile Penicillium sp. and as perinadine $\mathrm{A}^{13}$ from marine-derived Penicillium citrinum. The compounds show cytotoxicity against several cancer cell lines. However, this is the first report of the pyranoisochromone derivative isolated from Streptomyces. These results confirm that this sponge contains undiscovered microorganisms that possess the ability to produce new substances. We anticipate that this study will convince chemists that new species of Streptomyces can produce compounds containing unique skeletal structures and also encourage them to investigate such species.

\section{ACKNOWLEDGEMENTS}

This work was supported in part by the New Energy and Industrial Technology Development Organization of Japan (NEDO). We thank Mr Akihiko Kanamoto. OP BIO FACTORY Co., Ltd for his help in collecting the marine sponge samples.

1 Fenical, W. \& Jensen, P. R. Developing a new resource for drug discovery: marine actinomycete bacteria. Nat. Chem. Biol. 2, 666-673 (2006).

2 Lee, H. S. et al. Cyclic peptides of the nocardamine class from a marine-derived bacterium of the genus Streptomyces. J. Nat. Prod. 68, 623-625 (2005).

3 Mitova, M. I. et al. Evolving trends in the dereplication of natural product extracts. 2. The isolation of chrysaibol, an antibiotic peptaibol from a New Zealand sample of the mycoparasitic fungus Sepedonium chrysospermum. J. Nat. Prod. 71, 824-827 (2008).

4 Pimentel-Elardo, S. M., Gulder, T. A. M., Hentschel, U. \& Bringmann, G. Cebulactams $A 1$ and $A 2$, new macrolactams isolated from Saccharopolyspora cebuensis, the first obligate marine strain of the genus Saccharopolyspora. Tetrahedron Lett. 49, 68896892 (2008).

5 Motohashi, K., Takagi, M. \& Shin-ya, K. Tetracenoquinocin and 5-imino aranciamycin from a sponge-derived Streptomyces sp. Sp080513GE-26. J. Nat. Prod. (2010) doi:10.1021/np9007409.

6 Izumikawa, M., Khan, S. T., Komaki, H., Takagi, M. \& Shin-ya, K. JBIR-31, a new teleocidin analog, produced by a salt-requiring Streptomyces sp. NBRC 105896 isolated from a marine sponge. J. Antibiot. 63, 33-36 (2010).

7 Motohashi, K., Takagi, M. \& Shin-Ya, K. Tetrapeptides possessing a unique skeleton, JBIR-34 and JBIR-35, isolated from a sponge-derived actinomycete, Streptomyces sp. Sp080513GE-23. J. Nat. Prod. 73, 226-228 (2010).

8 Khan, S. T. et al. Distribution of the 3-hydroxyl-3-methylglutaryl coenzyme A reductase gene and isoprenoid production in marine-derived Actinobacteria. FEMS Microbiol. Lett. 304, 89-96 (2010). 
9 Izumikawa, M., Khan, S. T., Takagi, M. \& Shin-ya, K. Sponge-derived Streptomyces producing isoprenoids via the mevalonate pathway. J. Nat. Prod. 73, 208-212 (2010).

10 Altschul, S. F., Gish, W., Miller, W., Myers, E. W. \& Lipman, D. J. Basic local alignment search tool. J. Mol. Biol. 215, 403-410 (1990).

11 Furihata, K. \& Seto, H. Constant time HMBC (CT-HMBC), a new HMBC technique useful for improving separation of cross peaks. Tetrahedron Lett. 39, 7337-7340 (1998).
12 Stierle, A. A., Stierle, D. B. \& Kelly, K. Berkelic acid, a novel spiroketal with selective anticancer activity from an acid mine waste fungal extremophile. J. Org. Chem. 71, 5357-5360 (2006).

13 Sasaki, M., Tsuda, M., Sekiguchi, M., Mikami, Y. \& Kobayashi, J. Perinadine A, a novel tetracyclic alkaloid from marine-derived fungus Penicillium citrinum. Org. Lett. 7, 4261-4264 (2005). 